\title{
A Photocathode RF Gun Design for a mm-Wave Linac-Based FEL*
}

\author{
A. Nassiri, T. Berenc ${ }^{\dagger}$, J. Foster ${ }^{\dagger}$, G. Waldschmidt ${ }^{\dagger}$, and J. Zhou \\ Advanced Photon Source, Argonne National Laboratory \\ 9700 South Cass Avenue, Argonne, Illinois 60439 USA
}

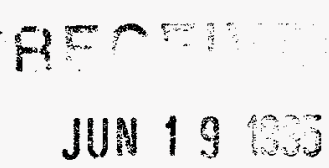

\section{Abstract}

In recent years, advances in the rf gun technoloy have made it possible to produce small beam emittances suitable for short period microundulators which take advantage of the low emittance beam to reduce the wavelength of FELs. At the Advanced Photon Source, we are studying the design of a compact $50-\mathrm{MeV}$ superconducting $\mathrm{mm}$-wave linac-based FEL for the production of short wavelengths $(-300 \mathrm{~nm})$ to carry out FEL demonstration experiments. The electron source considered for the linac is a $30-\mathrm{GHz}, 31 / 2$-cell $\pi$-mode photocathode if gun. For cold model if measurements a $15-\mathrm{GHz}$ prototype structure was fabricated. Here we report on the design, numerical modelling and the initial cold-model rf measurement results on the $15-\mathrm{GHz}$ prototype structure.

\section{INTRODUCTION}

Short wavelength FELs impose stringent requirements on the quality of the electron beams. The key factor in obtaining a single-pass UV or $x$-ray FEL is the generation of small emittance elcetron beams with ultra-high brightness. In the past decade, a termendous amount of R\&D has taken place to improve the performance of if gun design [1-2]. With the emergence of new photocathode materials with good quantum efficiencies and improvements in laser technology to produce ultra-short pulses, it is now possible to produce small emittance electron beams suitable for short wavelength FEL applications. The linac structure being considered is a $60-\mathrm{GHz}$ constant gradient superconducting stucture fabricated by using a precision microfabrication process known LIGA (Lithographie, Galvanoformung, Abformung).

The limitations on the emittance and beam brightness of an electron gun are mainly due to nonlinear electomagnetic forces, space charge forces, and the maximum current density that can be obtained from the cathode. Alkali semiconductors photocathode such as $\mathrm{Cs}_{3} \mathrm{Sb}$ can produce peak current density of $600 \mathrm{~A} / \mathrm{cm}^{2}$. These cathodes may be operated at pulse lengths ranging from a few picoseconds to microseconds at high pulse repitition rates. However, excellent vacuum $\left(\sim 10^{-9}\right.$ Torr ) must be maintained. Field emission array (FEA) cathodes could produce current density in excess of $100 \mathrm{~A} / \mathrm{cm}^{2}$. However, at the present time, their limited liftime due to various breakdown modes does not make them attractive for accelerator applications.

\footnotetext{
* Work supported by the U.S. Department of Energy, Office of Basic Energy Sciences, under Contract No. W-31-109-ENG-38.

$\uparrow$ Senior Research Students at Argonne.
}

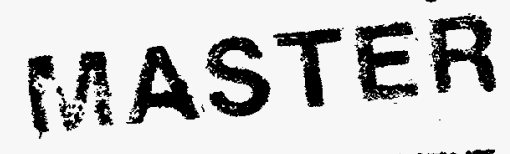

where $h(z)$ satisfies

$$
h(z)=\left(\frac{d^{2}}{d z^{2}}+p^{2}\right) E_{z}(z, o) .
$$

For ideal cavity shape it is required to make both $h(z)$ and $h^{\prime}(z)$ zero. In this case, the cavity's radius is given by [4]

$$
r=\sqrt{\left(a^{2}-\left(\frac{4 d}{\pi}\right)^{2} \log \left(\sin \frac{\pi z}{2 d}\right)\right)}
$$

As $\mathrm{z}$ goes to zero, it requires that $\mathrm{r}$ approaches infinity. In a real situation one can optimize the cells' geometry and the shape of the cavity around the exit in a way which is close to the ideal shape. The effects of nonlinear if forces and selffields of the electrons on the emittance growth of the electron beam has been described in detail by K.-J. Kim [5]. Emittance growth due to nonlinear $\mathrm{rf}$ forces can be controlled by ensuring that nonlinear transverse components of the rf fields are minimized. This can be achieved by placing a thick disk between cells and adjusting the diameter of the apertures so as to minimize nonlinear transverse components. The effects of nonlinear space charge forces are reduced since the initial electron distribution from the cathode are launched in a high gradient electric field and the space charge beam blowup scales as the inverse of the peak electric field gradient. For simulations, a laser pulse of $2 \mathrm{ps}$ is chosen. MAFIA [6] numerical codes were used to 


\section{DISCLAIMER}

This report was prepared as an account of work sponsored by an agency of the United States Government. Neither the United States Government nor any agency thereof, nor any of their employees, makes any warranty, express or implied, or assumes any legal liability or responsibility for the accuracy, completeness, or usefulness of any information, apparatus, product, or process disclosed, or represents that its use would not infringe privately owned rights. Reference herein to any specific commercial product, process, or service by trade name, trademark, manufacturer, or otherwise does not necessarily constitute or imply its endorsement, recommendation, or favoring by the United States Government or any agency thereof. The views and opinions of authors expressed herein do not necessarily state or reflect those of the United States Government or any agency thereof. 


\section{DISCLAIMER}

Portions of this document may be illegible in electronic image products. Images are produced from the best available original document. 
model the $31 / 2$-cell rf gun including particle-in-cell simulations. The main parameters of the prototype photocathode if gun are listed in Table 1.

Table 1: $15 \mathrm{GHz}$ Prototype Gun RF Parametters

\begin{tabular}{|l|l|}
\hline \multicolumn{1}{|c|}{ Parameter } & \multicolumn{1}{c|}{ Value } \\
\hline \hline Frequency & $15 \mathrm{GHz}$ \\
\hline Peak accelerating gradient & $200 \mathrm{MV} / \mathrm{m}$ \\
\hline Exit beam energy & $4 \mathrm{MeV}$ \\
\hline Charge per bunch & $1 \mathrm{nC}$ \\
\hline Cathode radius & $0.5 \mathrm{~mm}$ \\
\hline Emittance & $2 \mathrm{~mm}$-mrad \\
\hline Shunt impedance & $254 \mathrm{M} \Omega / \mathrm{meter}$ \\
\hline $\mathrm{Q}$ & 7000 \\
\hline
\end{tabular}

The gun's cell radius and aperture diameter were optimized to provide the correct longitudinal aceelerating field for the desired $\pi$-mode. For particle-in-cell simulations, a Gaussian bunch of 2-ps length (FWHM) and a total number of particles of $6 \times 10^{9}$ (total charge/bunch $=1 \mathrm{nC}$ ) is assumed to be ejected from the copper cathode surface of radius $0.5 \mathrm{~mm}$. The initial velocity of the bunch is assumed to be $v=0.01 \mathrm{c}$ with a peak If accelerating gradient of $200 \mathrm{MV} / \mathrm{m}$. Figure 1 shows the longitudinal field pattern for the accelerated bunched beam. Figure 2 is a plot of the particles energy ( $\gamma$-distribution) along the z-axis.

\section{PROTOTYPE GUN RF MEASUREMENTS}

The field perturbation method was employed to determine the axial field distributions of the excited modes in the $15-\mathrm{GHz}$ prototype if gun structure. The perturbation is achieved by using small cylindrical aluminum beads deposited on nylon lines and optical fibers with a diameter of $\sim 100 \mu \mathrm{m}$. A stepping motor with a $0.1-\mu \mathrm{m}$ minimum step size was used to pull the bead through the structure. For a bead having dimension that is small compared to the structure wavelength, the perturbation relation is given by [7]

$$
\frac{\Delta f}{f_{0}} \approx \frac{3 \Delta V}{4 U}\left[\varepsilon_{0}\left(F_{1}\left|E_{\|}\right|^{2}+F_{2}\left|E_{\perp}\right|^{2}\right)-\frac{\mu_{0}}{2}\left(F_{3}\left|H_{\| 1}\right|^{2}+F_{4}\left|H_{\perp}\right|^{2}\right)\right]
$$

where $E_{\|}\left(E_{\perp}\right)$ and $H_{\| 1}\left(H_{\perp}\right)$ are the electric and magnetic fields parallel (perpendicular) to the perturbing object axis and $F_{n}$ $(n=1,2,3,4)$ are the perturbational form factors. For a metallic sphere, these form factors are all equal to 1 [6].

The measurement setup (Figure 3) consists of two shorting plates located at the entrance and the exit of the structure to generate a standing wave field pattern. An on-axis hole was

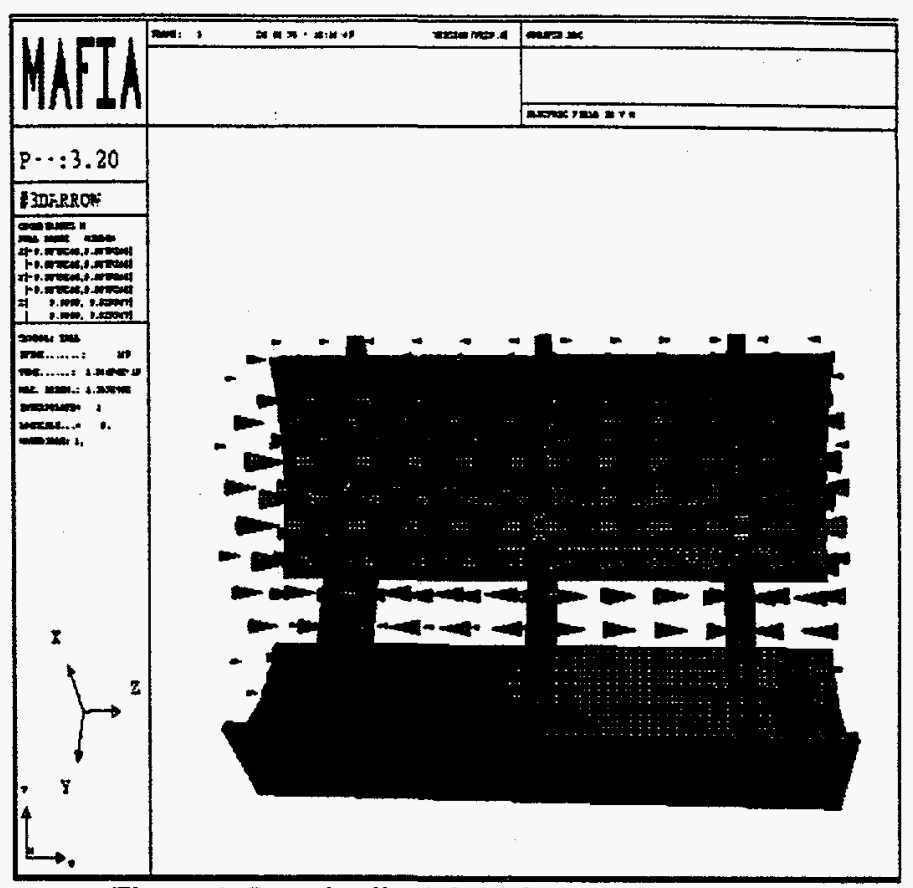

Figure 1: Longitudinal field for the accelerated beam

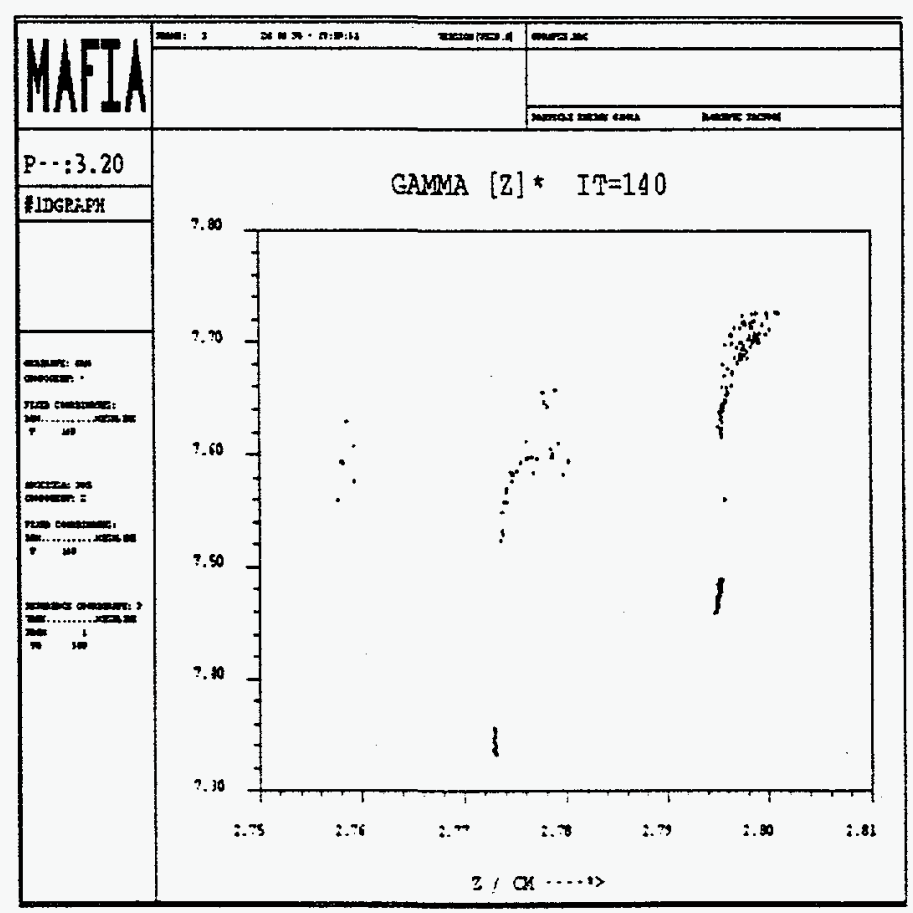

Figure 2: Particle beam energy distribution

drilled in each plate to provide an opening for the bead's travel path. To excite the longitudinal electric field, a field probe of 1.194- mm outer diameter was fabricated. An identical probe was used as a pickup. Two fiber chuck holders held the ends of the fiber line while the bead was pulled through the structure. The bead was advanced through the structure in small 
increments $(-94 \mu \mathrm{m} / \mathrm{step})$ through computer control of the stepper motor. At each bead position, the phase of the transmission coefficient, $S_{12}$, was measured using an HP 8510 network analyzer with an automatic data acuisition system. Figure 4 is the frequency spectrum of the excited modes in the structure.and Figure 5 is a plot of perturbation measurement results of the $\pi$-mode.

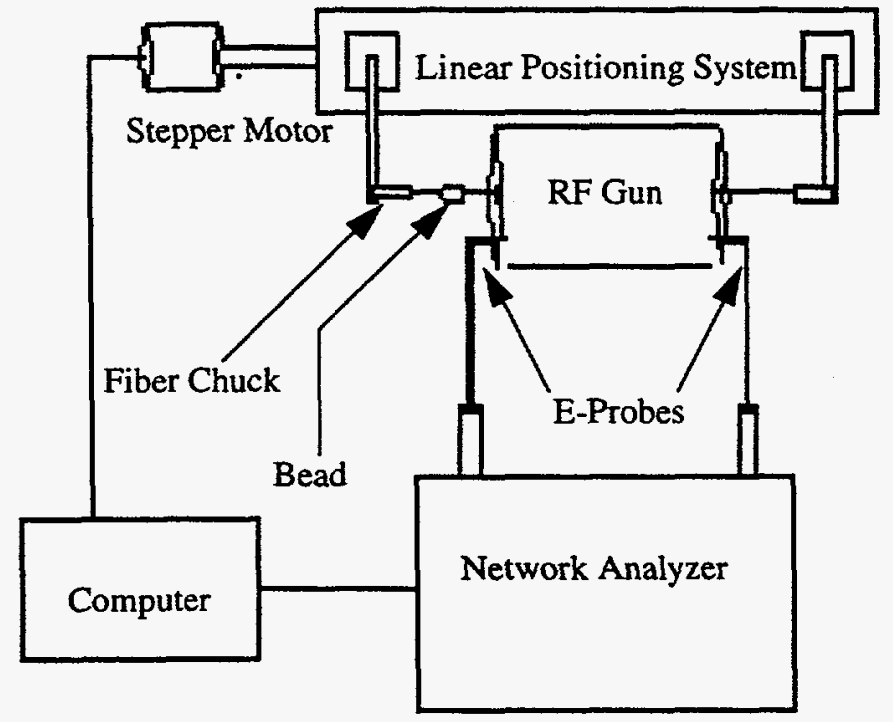

Figure 3: Bead pull field measurement setup

\section{SUMMARY AND DISCUSSION}

A $30-\mathrm{GHz}$ photocathode if gun is being considered as a low emittance electron source for a short-wavelength $50-\mathrm{MeV}$ single pass linac-driven FEL. To understand the if properties of high-frequency rf gun, a $15-\mathrm{GHz} 31 / 2$-cell copper structure was fabricated and bench tested. Numerical modeling result using MAFIA give a resonant frequency of $15 \mathrm{GHz}$ for the desired $\pi$-mode accelerating field with a shunt impedance of $254 \mathrm{M} \Omega / \mathrm{m}(\mathrm{Q}=7000)$. Beadpull measurements of the rf gun resulted in $15.5 \mathrm{GHz}$ for the $\pi$-mode with a shunt impedance of $3.4 \mathrm{M} \Omega / \mathrm{m}(\mathrm{Q}=312)$. The huge discrepancy beween the calculated and measured shunt impedance are mainly due to mechanical imperfections of the cavity during fabrication. This structure was fabricated in many separate pieces with relaxed tolerances and was put together in a "Lego-Block" manner and pressed fitted inside a copper block with a set of bolts and nuts to hold it together at both end. This resulted in poor if contacts between pieces (cells) which severely affected the if measurements. Improvements on the structural fabrication and measurement methods are planned.

\section{REFERENCES}

[1] R.L. Sheffield, E.R. Gray and J.S. Fraser,"The Los Alamos Photoinjector Program,"NIM A272 (1988) 222-226

[2] P. O'Shea, "High Brightness Photo-Cathode Guns for Single Pass X-Ray FELs, 16 th International FEL Conference, Stanford, CA, August 21-26, 1994.
[3] J. Gao, "Theoretical Investigation in the Optimization Design of Microwave Electron Gun," in Proc. 12th Free Electron LAser Conference, 1990.

[4] K. McDonald, "Design of the Laser-Driven RF Electron Gun for BNL Accelerator Test Facility," IEEE Trans. Electron Devices, vol. 35, no. 11, pp. 2052-2059, 1988.

[5] K.-J. Kim, Nucl. Instr. and Meth. A 250 (1986) 396.

[6] R. Klatt, et. al.,"MAFIA, A Three-Dimentional Electromagnetic CAD System," 1986 Linear Accelerator Conference Proc.., SLAC-303,276-278 (1986).

[7] L. C. Maier and J. C. Slater, "Field Strength Measurements in Resonant Cavities," Journ. Appl. Physics, vol. 23, pp. 68-77, 1952.

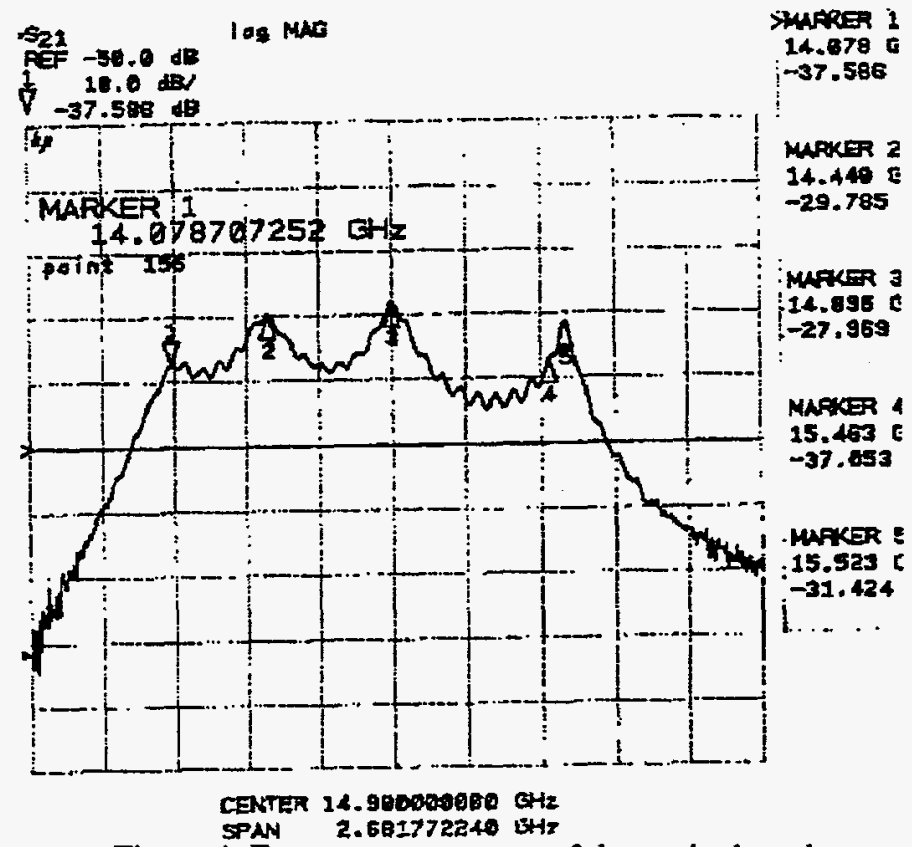

Figure 4: Frequency spectrum of the excited modes

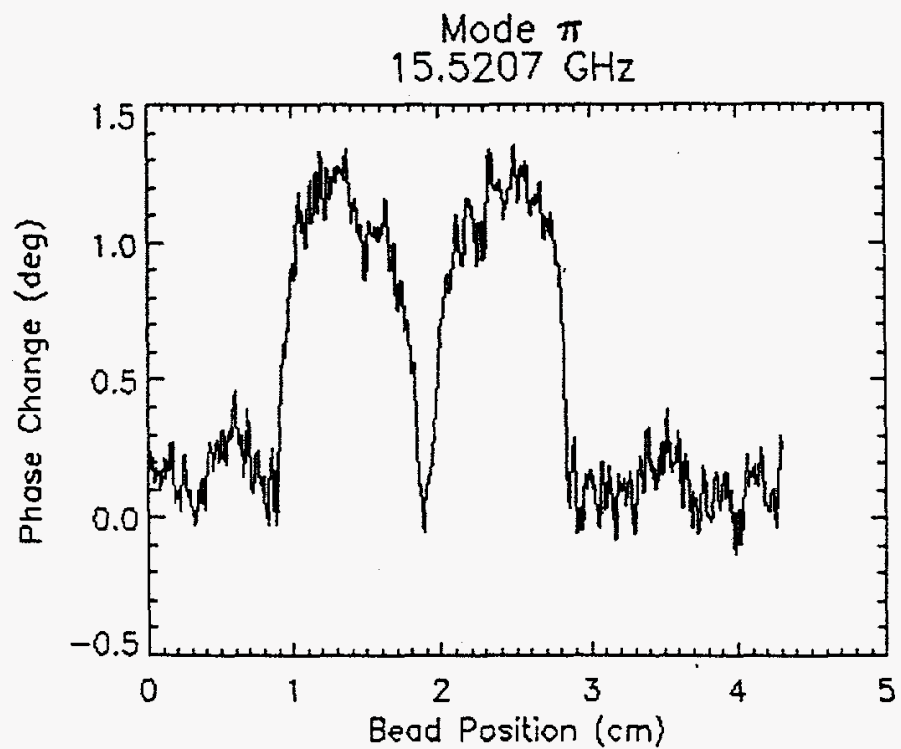

Figure 5: Perturbation measurement result for $\pi$-mode 